\title{
ИСТОРИЧЕСКИЕ ОСОБЕННОСТИ МИГРАЦИИ В СОЦИАЛЬНО- ПСИХОЛОГИЧЕСКОМ И ЭТНОКУЛЬТУРНОМ ИЗМЕРЕНИИ И ФАКТОР ФРУСТРАЦИИ
}

\begin{abstract}
Статья посвящена актуальной в научном и практическом отношении проблеме взаимодействия мигрантов с принимающим сообществом. Рассматриваются связанные с процессом миграции вызовы, прежде всего, опасность перевода сочиальных конфликтов в межэтническую плоскость, особенно в ситуаџии соџиальной нестабильности. Данная ситуаџия характерна в настоящее время для большинства стран мира, поэтому важна оченка воздействия на межэтнические отношения фактора фрустрации у тех или иньх групп населения. А выход из состояния фрустрации нередко переводится в сферу межэтнических отношений. Проблема особенно актуальна для таких полиэтничных государств, как Российская Федерация. Автор дает краткую характеристику феномена миграции на разных этапах истории, так как считает, что ее специфика зависит от стадиальных изменений в системе адаптации человека в среде обитания. Ведь миграчия непосредственно связана с адаптащией переселенцев к новым условиям жизни. Такой подход, по его мнению, помогает понять особенности современной миграции и вовремя предотвращцать возможные конфликтные ситуации.
\end{abstract}

Ключевые слова: этническая миграџия, адаптаџия мигрантов, фактор фрустрации, межэтнические конфликты

Ссылка при цитировании: Карлов В.В. Исторические особенности миграции в социально-психологическом и этнокультурном измерении и фактор фрустрации // Вестник антропологии, 2022. № 1. С. 59-69.

DOI: $10.33876 / 2311-0546 / 2022-1 / 59-69$

(C) V.V.Karlov

\section{THE SOCIO-PSYCHOLOGICAL AND ETHNO-CULTURAL DIMENSION OF THE HISTORY OF MIGRATION AND THE FRUSTRATION FACTOR}

The article is devoted to the problem of the interaction of migrants with the host community, which is relevant in scientific and practical terms. Migration is associated with various challenges; an important one is the danger of transferring social conflicts to the interethnic plane, especially in a situation of social instability. This situation

Карлов Виктор Владимирович - д.и.н., профессор кафедры этнологии исторического факультета, МГУ имени М.В. Ломоносова (119991 Москва, Ломоносовский просп., 27, корп.4). Эл. почта: vikarlov@mail.ru 
is currently typical for most countries of the world, so it is essential to assess the impact of the frustration factor on interethnic relations among certain groups of the population. The way out of frustration is often translated into the sphere of interethnic relations. The problem is especially relevant for such multi-ethnic states as the Russian Federation. The author gives a brief historical overview of the phenomenon of migration, as he believes that its specificity depends on the stage changes in the system of human adaptation to the environment. After all, migration is directly related to the adaptation of migrants to new conditions. This approach, in his opinion, helps to understand modern migration and prevent possible conflict situations in time.

Keywords: Ethnic migration, the adaptation of migrants, the factor of frustration, interethnic conflicts

For Citation: Karlov, V.V. 2022. The Socio-Psychological and Ethno-Cultural Dimension of the History of Migration and the Frustration Factor. Herald of Anthropology (Vestnik Antropologii) 1: 59-69.

Author Info: Karlov, Victor V. - Dr. (Hist.), Professor, Lomonosov Moscow State University (Moscow, RF). E-mail: vikarlov@mail.ru

Конец XX и начало XXI в. принесли человечеству серьезные перемены поистине глобального значения в организации жизни населения всех стран и народов. Эти изменения породили естественную потребность научного исследования различных аспектов мировых процессов, имеющего не только и даже не столько чисто научное, но еще более - практическое значение. К таким проблемам относится и миграция, которая приобрела колоссальные масштабы. Кроме стран, в значительной степени сформировавшихся как результат длительной и продолжающейся иммиграции (США, Австралия, Канада) и имеющих долю иммигрантов в населении от $20 \%$ и выше, сейчас эта доля стремительно растет и во многих государствах Старого света. В Европе, например, самый большой рост иммигрантов с 2010 по 2015 гг. был в Люксембурге, Швейцарии, Швеции, Австрии, Норвегии, Англии и Финляндии. Россия на середину 2010-х гг. по доле иммигрантов демонстрировала средние показатели (8,1\% от всего населения), однако в абсолютных цифрах это более 11,6 млн человек. И это не считая внутренней миграции, в нашей стране не менее интенсивной.

Таким образом, миграция стала одним из важнейших факторов феномена глобализации в мире, нуждающихся в изучении и анализе в самых разных аспектах. Она несомненно входит в круг исследовательских задач, обрисованных английскими исследователями глобальных перемен: «Глобализация может быть осмыслена как процесс (или совокупность процессов), который воплощает в себе трансформацию пространственной организации социальных отношений и взаимодействий - измеряемую с помощью таких показателей, как протяженность, интенсивность, скорость и воздействие, - порождающие межконтинентальные или межрегиональные потоки и структуры активности, взаимодействий и проявлений власти». Авторы говорят об «институализации (...) регулирования моделей взаимодействия, и, следовательно, их воспроизводства в пространстве и во времени». (Хелд и др. 2004: 19, 23 ).

Понятно, что изучение миграции в ее разнообразных проявлениях уже по причине сложности явления не может быть предметом какой-либо одной области науки. И 
закономерно, что изучением этих разных проявлений заняты сейчас многие отрасли научного знания. При этом ни одна из этих отраслей не может претендовать на исключительное место в их исследовании, ибо само явление многомерно и предполагает лишь комплексное постижение его сути в разных аспектах, включая экономику, политику, изменение систем расселения, культуру, этнический состав стран и континентов, и т.д. В таком многомерном освещении миграции есть свои преимущества: специальный подход к феномену с точки зрения различных наук в совокупности не только позволяет онтологически адекватно оценить явление, но и операционально выявить и проанализировать рожденные миграцией вызовы обществу и практики регулирования процессов. Специалисты, занятые исследованием современных процессов миграции, проанализировав посвященную ей мировую литературу, предлагали классификацию направлений, теорий и подходов в изучении связанных с ней проблем. Выделены, в частности, такие концепции как культурологическая, этносоциологическая, конфликтологическая, географическая, урбанистическая, историко-демографическая, этнологическое и системно-типологическое направления, и т. д. (Ионцеев 2014: 63-83).

Среди различных подходов к явлению названы этнологический и этносоциологический (в широком смысле их можно объединить в историко-культурный) контексты, что естественно. В историко-культурных и этнографических ракурсах явление миграции, конечно, многократно описывалось на различном реальном историческом материале. В анализе этнокультурной составляющей миграции преобладает чаще всего рассмотрение ситуации контакта конкретных этнических групп населения в локально-региональном аспекте. Это объяснимо и закономерно: только конкретный материал в его вариациях может создать основу для целостной характеристики современной миграции.

Связь явления миграции в социально-психологическом и этнокультурном аспектах с фактором фрустрации, вынесенные в заглавие статьи, по мнению автора, нуждается не только в изучении конкретно-локальных проявлений. Процесс адаптации мигранта, сопряженный с этими аспектами, есть неизбежное сопровождение процесса миграции, что очевидно. Так же очевидно, что отрыв человеческих сообществ и человека от привычных среды обитания и образа жизни неизбежно сопровождается психологическими перегрузками и может иметь различное выражение. Среди типичных проявлений этих нагрузок и перегрузок можно назвать фактор фрустрации, который представляется одним из самых социально опасных следствий контактов мигрантов с принимающим обществом. Связь адаптации и фрустрации довольно объяснима, ведь адаптация мигранта - это всегда поиск нового «места под солнцем». Если поиск будет проходить с большими трудностями, это уже причина воздействия на человека фрустрирующих обстоятельств. Причем такие обстоятельства могут возникать и в среде принимающего мигрантов сообщества, когда складывается ситуация конкуренции (например, в трудоустройстве, поисках жилья и др.).

Здесь нелишне напомнить определение явления фрустрации психологами. Это состояние дезорганизации сознания и деятельности человека, которое возникает у него в основном тогда, когда мотивы его деятельности не могут по каким-либо объективным или субъективным причинам быть удовлетворены. Но так как долго сознание личности не может находиться в состоянии дезорганизации, человеческая психика ищет выход из него. А типичным примером выхода бывает поиск «козла отпущения» - перенос недовольства своими трудностями в решении проблем на не- 
кий внешний объект. Опасность фрустрации в ситуации с мигрантами состоит в том, что в полиэтничной среде «козлом отпущения» часто оказываются представители иноэтничной группы, как правило, даже независимо от того, где происходит взрыв негатива, в принимающем или принимаемом сообществе. И то, что реальной причиной практически всегда оказываются вовсе не этнические, но чисто социальные обстоятельства, к сожалению, совершенно не спасает от межэтнических «выплесков» негативных реакций.

Приоритет сугубо социальных, а вовсе не этнокультурных причин действия механизма фрустрации наглядно подтверждается, в частности, ярким примером, приведенным армянскими этнопсихологами при анализе опроса населения Еревана. При анкетировании жителей Еревана была выявлена часть населения, у которой зафиксирован негативный автостереотип. Когда исследователи стали выяснять, что собой представляет и из кого состоит данная категория респондентов, то обнаружилось, что это армяне - жители Еревана, у кого сложились большие проблемы изза неустроенности в жизни. Таким образом, испытывая состояние фрустрации, они свои неудачи связали с якобы отрицательными качествами собственного народа. Но это, справедливо отметили исследователи, возможно в Ереване, городе по существу мононациональном. В любой же полиэтничной среде «козлом отпущения» - виновником невзгод непременно становятся люди иной национальной принадлежности (Население Еревана 1986: 208-210).

В подтверждение последнего тезиса можно привести длинный список конфликтов в пределах России и бывших республик СССР за последние пару десятилетий, в которых так или иначе был задействован межэтнический фактор, перенаправленный в эту плоскость от сугубо социальных причин недовольства. В наше время серьезных перемен в самых разнообразных аспектах жизни общества и его организационных связей, сопровождающихся нестабильностью положения многих групп населения, соответственно возрастает и опасность такого рода выходов из состояния фрустрации в неприемлемых и сопряженных с жертвами формах, справиться с которыми часто удается лишь «силовыми» методами.

Все такие ситуации имеют конкретные причины и проявления. Однако, чтобы отчетливо представлять именно современную специфику вызовов обществу, связанных с реакциями на фрустрацию, автор считает полезным коротко охарактеризовать специфику процессов миграции в исторической динамике, их базовые различия в хронологическом аспекте, связанные со стадиальными особенностями процессов адаптации мигрантов. Такие базовые хронологические отличия более всего зависят, на мой взгляд, от специфики трех основных способов адаптации человеческих сообществ в среде обитания, которые прошло или ныне проходит человечество.

Первый из способов - характерная для доиндустриального периода специализированная тем или иным образом деятельность по натуральному жизнеобеспечению. Именно специфический вариант натурального жизнеобеспечения есть ведущая связь, которая консолидирует этнос, а язык и культурно-бытовые формы лишь результат выработки данного способа адаптации в среде и механизмов его трансмиссии следующим поколениям.

Второй в истории специализированный способ адаптации в среде обитания связан с эпохой модерна или индустриализации. Здесь натуральное самообеспечение, бывшее основой этнической связи, меняется на систему, в которой способ адапта- 
ции связан с дробно дифференцированной и профессионально специализированной деятельностью и обменом ее результатами через рынок. Сначала это происходит в моноэтнической среде, которая становится ядром развития новой связи. Но затем постепенно в систему включаются и иноэтничные группы или их части. Эта новая связь становится основной для такого сообщества как национальная общность, или нация - главный субъект адаптации в среде для входящих в нее людей, постольку поскольку именно в ее пределах складывалась система дифференцированной деятельности и обмена ее результатами, жизненно необходимая для реализации насущных потребностей людей, принадлежащих к сообществу-нации.

С конца XX в. в мире происходит становление нового, третьего по счету, специализированного способа адаптации в среде обитания, названного глобализацией. Его специфическими особенностями можно назвать расширение социально-воспроизводственных связей и обеспечивающих их функционирование институтов до мировых масштабов, перешагивание ими национально-государственных границ (не говоря уже об этнических). Появляются признаки функционально работающих механизмов, ориентированных на различные потребности человека в жизнеобеспечении и услугах разного рода, которые некоторыми исследователями конца прошлого века названы «эргатической системой» (от греческого «эргасиа»- «работа»). Эта система - некое триединство «индивид - социум - техника», где социум представлен институциями сферы услуг определенного узкоцелевого назначения, при помощи технических средств, обеспечивающих потребности индивида (Дружинин и др. 1989).

Первый названный этап - адаптация в среде обитания посредством специализированного способа натурального жизнеобеспечения - занимал длительный период от неолита до позднего средневековья и начала модернизации. Миграции были свойственны всему этому периоду истории. Вызывались они в основном либо изменениями климата, либо ростом населения и необходимостью расширения территории обитания народов. Эти перемещения в той или иной степени отразились на формировании всех народов. Как писал по этому поводу С.А. Токарев еще в 1949 г., «в числе современных народов нет ни одного, который не был бы смешанным по своему происхождению. Есть только народы более или менее смешанного происхождения, но нет или почти нет народов, избежавших смешения. Исключения крайне редки» (Токарев 1999: 38). То есть каждый современный народ сформировался в той или иной мере в результате процессов миграции, что служит предметом детального этнологического, археологического и лингвистического анализа истоков и хода влияния миграций на его происхождение и состав.

Формы контакта принимающего и принимаемого сообществ в ситуации господства натурального жизнеобеспечения были не слишком разнообразны. Очень часто итог контакта зависел, как достаточно хорошо известно из источников, от военной силы обеих контактирующих сторон. Если сила была на стороне мигрантов, дело оборачивалось либо вытеснением, либо истреблением «аборигенов». Ведь по существу взаимодействовали две культуры, каждая из которых была самодостаточна и не нуждалась в заимствованиях ни в технологическом, ни в нормативно-регулирующем отношении. Если же какая-либо из сторон контакта была относительно малочисленной, был возможен и синтез, заимствование в способах жизнеобеспечения, особенно из местного опыта принимающей переселенцев стороны. Такими примерами богата история культуры многих народов. Возможен был также вариант, когда многочис- 
ленный и сильный, или преобладающий в военном отношении, участник взаимодействия обращал более слабого в зависимое сословие. Разумеется, угнетаемая часть испытывала фрустрацию, а если угнетатели представляли иную этническую группу, то против них нередко вспыхивали восстания и бунты, хорошо известные из истории.

В «пережиточном» варианте контакт двух самодостаточных участников взаимодействия, оба из которых сохраняют, хотя бы частично, свой этнически специфичный комплекс способов деятельности и нормативной практики, из такого комплекса вытекающей, можно встретить даже в настоящее время. Такое иногда случается при переселениях людей из одного региона в другой, если это сельские миграции. Тогда требуется определенное время на привыкание, «притирку» мигрантов и старожилов друг к другу. Для города, где виды деятельности уже давно профессионально специализированы и где осталось мало места для их этнической специфичности, такое, конечно, не характерно. Переселенцу, в той или иной степени еще сохранившему сельские стереотипы, в этих обстоятельствах волей-неволей приходится пройти определенную ресоциализацию.

Впрочем, и в доиндустриальную эпоху известны варианты, когда постепенно оба контактирующих этнических компонента со временем формировали некий общий этнокультурный уклад, ориентированный на натуральное жизнеобеспечение, а неравенство, если оно при этом имело место, приобретало не этническое, а лишь социально-сословное различие.

Интересно и по-своему показательно, что, по материалам физических антропологов, в процессе восточно-славянской колонизации установка на мирные взаимоотношения с обитателями колонизуемых территорий входила в «стратегию выживания» восточных славян на новых местах. Такая психологическая установка действительно была присуща им и в относительно позднее время. Например, исследователь национальных отношений в царской России А. Каппелер отмечал, что среди многонационального населения Средней Волги XIX в. именно русские крестьяне были наиболее открыты для межэтнического общения (Kappeler 1982: 495). Показателем такой установки можно считать и то, что, попадая в резко отличные от привычных природно-климатические области, русские колонисты относительно легко перенимали от автохтонов многие их способы жизнеобеспечения, также как и им передавали свои хозяйственные навыки, имевшие какие-то преимущества. Вероятно, и этим можно объяснить формирование гигантской территории многонациональной империи, для населения которой межкультурное взаимодействие и взаимовлияние проявлялось во многих формах.

С переходом к эпохе модерна изменяется прежде всего сам способ адаптации в среде. Специализированное натуральное жизнеобеспечение (причем специализированное определенным этнически специфичным образом) меняется на профессионально дробную дифференцированную систему деятельности и обмена, и уже вся эта сложная конструкция в целом становится основой жизнедеятельности всего сообщества-нации. О типологическом отличии феноменов этноса и нации друг от друга достаточно давно и весьма доходчиво высказался выдающийся испанский философ Х. Ортега-и-Гассет: «Единство нации, прежде всего, подразумевает налаживание тесной взаимосвязи между этническими и политическими группами. Но этого мало. По мере развития государства, усложнения государственных потребностей растет дифференциация социальных функций и, стало быть, соответствующих органов. Внутри единого целого возникает ряд миров, где царит своя, неповторимая атмосфера, то 
есть имеются свои нормы, интересы, обычаи, идеи и настроения. Это миры военных, политиков, промышленников, ученых и творцов, рабочих и т.д. Словом, процесс объединения, в результате которого образовалось единое крупное государство, уравновешивается разделением общества на классы, слои, социальные группы.

Все этнические сообщества, прежде чем войти в государство, существовали отдельно. Каждое из них было самостоятельной единицей. Наоборот, классы и социальные группы изначально представляли собой части целого. Первые, так или иначе, могут вернуться к независимости. Вторые никогда не жили и не могут жить сами по себе. Вся их суть в том, чтобы быть частями целого, элементами структуры, в которую жестко вписано их существование. Так делец нуждается в поставщиках сырья, в покупателях, в администрации, которая наводит порядок на дорогах, в военных, призванных этот порядок защищать. В свою очередь, мир военных, или «защитников» (...) нуждается в предпринимателе, крестьянине, технике.

Нация живет нормальной жизнью, когда каждая из групп понимает, что она только часть общества (Ортега-и-Гассет 1994: 47-48).

В способе адаптации, рожденном эпохой модерна, появляется очень важная особенность как для всего населения государства, так и для мигрантов. Она заключается в том, что в ряду идентичностей, свойственных индивиду, на одно из первых мест выходят идентичности профессиональная, а также сословно-классовая, значимость же этнической хотя и сохраняется, но уменьшается, во многих ситуациях уступая иным формам. Социологи давно пришли к заключению, что в обществе модерна, где индивид имеет несколько актуальных для себя идентичностей, идентификация как правило ситуативна. То есть в зависимости от конкретной ситуации на первое место выходит та идентичность, которая в данных обстоятельствах наиболее выгодна для человека. Это особенно типично для высоко урбанизированных обществ, где в основном наиболее актуальны социально-профессиональные характеристики. Что обычно создает для мигранта более комфортную ситуацию. Если же человек из иной этнической среды, чем большинство, с которым приходится контактировать, практически постоянно позиционирует себя по иным критериям, чем этническая принадлежность, то это, вероятно, становится одним из факторов его ускоренной ассимиляции в принимающем обществе. Ассимиляция такого рода не всегда означает перемену этнической идентичности. Но постепенно может вести и к ее смене на иную.

В результате мигранты получают потенциальную возможность более легкого включения в национально-государственную структуру дифференцированной деятельности и обмена, вписываясь в национальное сообщество в первую очередь как представители профессии. Понятно, что для обустройства в районах миграции профессиональная идентичность уже более значима, чем этническая принадлежность. Особенно это касается специалистов высокого профессионального уровня.

Разумеется, между возможностью и реальностью существенная разница, однако наличие возможности само по себе уже достаточно значимо. Конечно, рядовая масса мигрантов, не обладая сверхвысокой квалификацией, не может рассчитывать на благоприятное решение проблемы трудоустройства и вынуждена довольствоваться такими рабочими местами, которые в принимающем сообществе считаются непрестижными. Иногда на этой почве возникают локальные районы, своего рода гетто, где вынуждены селиться мигранты. Такие ситуации в крупных городах Европы и США хорошо описаны в литературе (Яниизкий 1975). Теперь же нечто подобное можно наблюдать и 
в городах России. В советское время такого не наблюдалось, впрочем, во многом потому, что существовали строгие ограничения прописки в крупных городах, а потому иноэтничным мигрантам делалось исключение чаще как раз по причине их высокой профессиональной квалификации. А ситуации большого скопления переселенцев с низкой квалификацией и, соответственно, многими неудовлетворенными жизненными потребностями, всегда чреваты взрывами конфликта с коренным населением, какая сторона ни становилась бы реальным или мнимым виновником взрыва.

При всей сложности социального и этнического состава современных трудовых мигрантов в условиях России, появление значительного числа переселенцев, особенно в занятом населении мегаполисов, создает ряд проблем не только с трудоустройством, но и во многих бытовых аспектах. Все это, конечно, по-разному, но воздействует на самоидентификацию мигрантов. Справедливо высказанное рядом авторов мнение о том, что происходящие в процессе устройства мигрантов изменения идентичности важны не только для них самих, но и как составляющая часть становления гражданского общества в стране (Выхованеи и др. 2014).

Не менее, если не более, важна постоянная работа социально-психологического характера и с принимающим мигрантов сообществом. Не секрет, что усиление миграционных потоков в мире, в частности, в Европе, вызвало на фоне отсутствия реального и эффективного решения на уровне правительств и муниципалитетов комплекса многочисленных проблем определенные настроения «мигрантофобии». Политическое же кредо мультикультурализма, звучавшее как красивый лозунг, не имело под собой программы или практической модели воплощения в бытовой плоскости. Во многом именно поэтому высказывалось не лишенное оснований мнение о том, что идеологически мультикультурализм есть замена расизма биологического «дифференциальным» культурным расизмом, ибо только номинально провозглашает равенство культур и их право на существование, но вообще не касается вопросов их реального взаимодействия (Балибар, Валлерстайн 2003: 27-38).

В России политика мультикультурализма хотя и не была принята как официальная доктрина, однако общие настроения мигрантофобии не только имеют иногда бытовые проявления, но временами проглядывают даже в материалах СМИ, не говоря уже об интернете. На бытовом уровне сложившееся не вполне лояльное отношение к мигрантам из зарубежных стран не так уж редко переносится и на внутренних мигрантов, для которых русский язык не является родным. Такие факты неоднократно отмечались в литературе о мигрантах. Например, выходцы с Северного Кавказа в Москве нередко воспринимаются не как соотечественники, а как граждане другого государства (Дробижева 2014; Галяпина 2015). Конечно, все подобные ситуации, особенно при контакте лиц, не привыкших к несколько отличным от собственных норм поведения, создают почву для конфликта.

Такая ситуация с взаимодействием мигрантов и принимающего сообщества на массовом уровне сохраняется и представляет собой висящий над обществом «дамоклов меч», в любой момент готовый нанести разящий удар. Однако постиндустриальная цивилизация открывает ряд принципиально новых возможностей адаптации: одно из последствий глобализации - рождение «эргатической системы», глобальный рост места и значения в жизнедеятельности общества сферы услуг, ориентированных на удовлетворение жизненных потребностей индивида с опорой на современные технические возможности. Какое это имеет значение для мигрантов? Разумеется, наиболее полное 
удовлетворение жизненных целей, как и сиюминутных потребностей человека, зависит от таких мест обитания, где сферы услуг наиболее развиты и, конечно, от финансовой состоятельности индивида-потребителя услуг. В современных условиях такая состоятельная часть мигрантов, как правило, легко находит «место под солнцем», даже без опоры на какие-либо стабильные социальные связи, в том числе этнического характера.

Другой гранью адаптации в наше время можно назвать изменение места стабильных идентичностей в деятельности крупных современных корпораций, на что обратили внимание некоторые исследователи. Речь идет о том, что человек, воспринимавшийся как маргинал (а многие из мигрантов волей-неволей испытывают состояние маргинальности) уже не своего рода «культурный изгой», как он воспринимался еще недавно, но, скорее, новый «культурный герой»: такой «глобальный игрок» без константных культурных «привязок» удобен для роли международного менеджера, руководителя нового типа, находясь как бы между многими культурами, но «в центре мира». Он не имеет стабильных культурно-ценностных ориентиров, и потому, вероятно, способен более гибко оперировать и манипулировать клиентами и контрагентами в корпоративных интересах (Moosmüller 1998: 199). Вероятно, в этих наблюдениях, по-видимому, есть рациональное зерно. Не случайно в сюжетах многих современных сериалов обыгрывается сверхуспешная карьера «лишенных комплексов» провинциалов, благополучно нашедших работу в крупных столичных фирмах.

Однако же новые возможности, открываемые перед мигрантами в условиях глобализации, перекрываются пока и новыми вызовами, или обновленными старыми. Здесь имеются ввиду обстоятельства резкой смены среды жизнедеятельности для части мигрантов, не располагающих возможностями быстро вписаться в новую среду. Это нередко ведет не столько к возникновению новых групповых связей, сколько к возрождению старых идентичностей и связей в новых условиях, причем с усилением их роли и значения в сравнении с прошлым, что убедительно проиллюстрировал, например, С. Хантингтон, объясняя корни исламского фундаментализма на Ближнем Востоке в конце XX в. утратой прежних общинных связей в новой урбанизируемой среде (Хантингтон 2006: 144-145). Такая ситуация имеет место и среди мигрантов из Азии в странах Европы, где расчеты на успех политики мультикультурализма потерпели фиаско, столкнувшись с практикой.

В основе подобного психологического состояния сообществ как мигрантов, так нередко и принимающего их населения - неопределенность и нестабильность. Как справедливо отмечал известный российский социолог В.А. Ядов, анализируя состояние общества в связи с крушением советского строя, в условиях нестабильности резко возрастает потребность человека в социальных связях - солидарности, идентичности, принадлежности к группе. А нетерпимость к неопределенности есть одна из самых сильных психологических характеристик человека, способствующая его адаптации в жизни (Ядов 2010; Данилова, Ядов 2004). Самое же опасное следствие неопределенности в полиэтничной среде - это то, что она вызывает ощущение фрустрации и у мигрантов, и у коренного населения. Один из наглядных примеров этого - для многих неожиданный успех новой партии АДГ в Германии, особенно среди восточных немцев. Но это как раз хорошо объясняется «двойной» фрустрацией немцев этих областей: мало того, что они уже не первое десятилетие после воссоединения ФРГ и ГДР (а точнее фактического поглощения последней) ощущали себя гражданами второго сорта, так еще к этому добавилось более лояльное отношение власти к мигрантам, чем к ним. 
Понятно, что основная причина опасности фактора фрустрации для российского общества это в первую очередь не преодоленная нестабильность его состояния. Поэтому малейшая социальная диспропорция в любой момент может быть перенесена на межэтническую почву и обернуться взрывом. Избежать этого практически невозможно, пока нестабильность будет сохраняться. А сохраняться она будет долго, ибо весь мир вступил в полосу нестабильности. Единственное, чем общество может способствовать снижению этой опасности - это создание службы, обязанной отслеживать возникновение напряженных ситуаций. Для этого необходима подготовка профессиональных этнологов, этносоциологов, этнопсихологов, социальных антропологов для работы в административных органах вплоть до муниципального уровня. Средства для их подготовки найти в любом случае легче, чем потом преодолевать последствия неконтролируемых конфликтов.

\section{Научная литература}

Балибар Э., Валлерстайн И. Раса, нация, класс. Двусмысленные идентичности. М.: Логос-Альтера. 2003. С. 27-38.

Выхованец О.Д., Прохорова А.В., Савинкова Ю.К., Старчак М.В., Яиенко Е.Б. Трансформация идентичности мигрантов как одна из составляющих становления гражданского общества в России. М.: Фонд «Наследие Евразии», 2014.

Галяпина В.Н. От соотечественника к «чужому»: образ этнического мигранта в восприятии москвичей (по результатам фокус-групповых дискуссий) // Общественные науки и современность, 2015, №2. С. 72-83.

Данилова E.Н., Ядов В.А. Нестабильная социальная идентичность как норма современных обществ // Социологические исследования, 2004, №10. С. 27-30.

Дробижева Л.М. Этническая солидарность, гражданская консолидация и перспективы межэтнического согласия в Российской Федерации // Общественные науки и современность, 2014, №1. С. 119-129.

Дружинин В.В., Конторов Д.С., Конторов М.Д. Введение в теорию конфликта. М.: Радио и связь, 1989.

Ионцев B.A. Классификация основных теоретических подходов в изучении миграции населения // Миграция в России. 2000-2012. Хрестоматия в 3-х томах. Т.1, ч.1. М.: Спецкнига, 2013. C. 63-83.

Население Еревана. Этносоциологические исследования. Отв. ред. Ю.В. Арутюнян, Э.Т. Карапетян. Ереван: изд-во АН АрмССР, 1986. С. 208-210.

Ортега-и-Гассет X. Этюды об Испании. Киев: Новый Круг: Пор-Рояль, 1994. С. 47-48.

Токарев С.А. К постановке проблем этногенеза // Токарев С.А. Избранное. Теоретические и историографические статьи по этнографии и религиям народов мира. Т.1. М.: ИЭА РАН, 1999. С. 38.

Хантингтон С. Столкновение цивилизаций. М.: АСТ. 2006. С. 144-145.

Хелд Д., Гольблатт Д., Макгрю Э., Перратон Дю. Глобальные трансформации. Политика, экономика и культура. М.: Праксис, 2004.

Ядов В.А. Какие теоретические подходы полезны для понимания и объяснения социальных реалий российского общества и России? // Россия реформирующаяся. Ежегодник, вып. 9. М.: Новый хронограф, 2010. С. 20-23.

Яниикий О.Н. Урбанизация и социальные противоречия капитализма. Критика американской социологии. М.: Наука, 1975.

Kappeler A. Russlands erste Nazionalitäten. Das Zarenreich und die Völker der Mittleren Wolga vom 16 bis 19 Jahrhundert. Köhln, Wien. 1982. 495 p.

Moosmüller A. Interkulturelle Kommunikation und globale Wirtschaft: zu den Risiken und Chancen von kultureller Differenz // Schweizerisches Archiv für Volkskunde. Zürich. 1998. No. 2. Pp. 199. 


\section{References}

Arutiunian, Iu.V., Karapetian E.T. (ed.). 1986. Naselenie Erevana. Etnosotsiologicheskie issledovaniia. [The population of Yerevan. Ethnosociological research]. Erevan: Izdatelstvo AN ArmSSR.

Balibar, E., Vallerstain, I. 2003. Rasa, natsiia, klass. Dvusmyslennye identichnosti [Race, nation, class. Ambiguous Identities]. Moscow: Logos-Al'tera.

Danilova, E.N., Iadov, V.A. 2004. Nestabil'naia sotsial'naia identichnost' kak norma sovremennykh obshchestv [Unstable social identity as a norm of modern societies]. Sotsiologicheskie issledovaniia 10: 27-30.

Drobizheva, L.M. 2014. Etnicheskaia solidarnost', grazhdanskaia konsolidatsiia i perspektivy mezhetnicheskogo soglasiia v Rossiiskoi Federatsii [Ethnic solidarity, civil consolidation and prospects for interethnic harmony in the Russian Federation]. Obshchestvennye nauki i sovremennost' 1: 119-129.

Druzhinin, V.V., Kontorov, D.S., Kontorov, M.D. 1989. Vvedenie v teoriiu konflikta [Introduction to Conflict Theory]. Moscow: Radio i sviaz'.

Galiapina, V.N. 2015. Ot sootechestvennika k "chuzhomu': obraz etnicheskogo migranta v vospriiatii moskvichei (po rezul'tatam fokus-gruppovykh diskussii) [From a compatriot to a "stranger": the image of an ethnic migrant in the perception of Muscovites (based on the results of focus group discussions]. Obshchestvennye nauki i sovremennost' 2: 72-83.

Iadov, V.A. 2010. Kakie teoreticheskie podkhody polezny dlia ponimaniia i ob"iasneniia sotsial'nykh realii rossiiskogo obshchestva i Rossii? [What theoretical approaches are useful for understanding and explaining the social realities of Russian society and Russia?] Rossiia reformiruiushchaiasia. Ezhegodnik. Moscow: Novyi khronograf 9: 20-23.

Ianitskii, O.N. 1975. Urbanizatsiia i sotsial'nye protivorechiia kapitalizma. Kritika amerikanskoi sotsiologii [Urbanization and social contradictions of capitalism. Criticism of American Sociology]. Moscow: Nauka.

Iontsev, V.A. 2013. Klassifikatsiia osnovnykh teoreticheskikh podkhodov v izuchenii migratsii naseleniia [Classification of the main theoretical approaches in the study of population migration] In Migratsiia v Rossii. 2000-2012. Khrestomatiia v 3-kh tomakh [Migration in Russia. Textbook in 3 books]. Book 1, ch. 1. Moscow: Spetskniga.

Khantington, S. 2006. Stolknovenie tsivilizatsii [The Clash of Civilizations]. Moscow: AST.

Kheld, D., Gol'blatt, D., Makgriu, E., Perraton, Dzh. 2004. Global'nye transformatsii. Politika, ekonomika i kul'tura [Global Transformations. Politics, Economics and Kultura]. Moscow: Praksis.

Kappeler, A. 1982. Russlands erste Nazionalitäten. Das Zarenreich und die Völker der Mittleren Wolga vom 16 bis 19 Jahrhundert. Köhln . [The first nationalities in Russia. The Tsarist Empire and the peoples of the Middle Volga region from the 16th to the 19th centuries.]. Wien.

Moosmüller, A. 1998. Interkulturelle Kommunikation und globale Wirtschaft: zu den Risiken und Chancen von kultureller Differenz Schweizerisches [ Intercultural communication and the global economy: on the risks and opportunities of cultural differences]. Archiv für Volkskunde 2: 199.

Ortega-i-Gasset, Kh. 1994. Etiudy ob Ispanii [Sketches about Spain], 47-48. Kiev: Novyi Krug: Por-Roial'.

Tokarev, S.A. 1999. K postanovke problem etnogeneza [On the formulation of problems of ethnogenesis] In Tokarev, S.A. Izbrannoe. Teoreticheskie i istoriograficheskie stat'i po etnografii $i$ religiiam narodov mira [Favourites. Theoretical and historiographical articles on ethnography and religions of the peoples of the world]. Book.1. Moscow: IEA RAN.

Vykhovanets, O.D., Prokhorova, A.V., Savinkova, Iu.K., Starchak, M.V., Iatsenko, E.B. 2014. Transformatsiia identichnosti migrantov kak odna iz sostavliaiushchikh stanovleniia grazhdanskogo obshchestva $v$ Rossii [Transformation of migrants' identity as one of the components of the formation of civil society in Russia]. Moscow: Fond 'Nasledie Evrazii'. 